\title{
Motivational Factors and Intended Efforts in Learning East Asian Languages Among Thai Undergraduate Students
}

\author{
Luoling Yang \\ Faculty of Liberal Arts, Mahidol University, Nakhon Pathom, Thailand \\ Natthapong Chanyoo \\ Faculty of Liberal Arts, Mahidol University, Nakhon Pathom, Thailand
}

\begin{abstract}
The objective of the current study was to investigate undergraduate students' motivation in learning three East Asian languages (Chinese, Japanese, and Korean), with intended effort used as a measure of motivation, based on Dörnyei's L2MSS theory (2005) and five other predictors. The study's participants were 95 undergraduate students, recruited by convenient random sampling on a voluntary basis, eight of whom volunteered to participate in interviews. Descriptive data and Pearson correlations were used to identify language learning motivations and the relationship between predictors and the intended effort, while a qualitative content analysis was used to support quantitative findings. The results revealed that the participants showed high levels of motivation in learning East Asian languages. A strong linear relationship was found between L2 learning experience, with all languages studied, and the ideal L2 self component. Moreover, the factor of intended effort had a positive relationship with instrumentality-promotion $(r=.651, p$ $=.000)$, international posture $(r=.275, p=.003)$, and cultural/community interest $(r=.426, p=.000)$ in Chinese learners, cultural/community interest $(r=.433, p=.015)$ in Japanese learners, and international posture $(r=.446, p=.015)$ in Korean learners. Nonetheless, instrumentality-prevention and intended effort were negatively related in Japanese learners $(r=-.420, p=.019)$. The study recommends a comprehensive study be undertaken to investigate the role of $\mathrm{L} 2$ learning experience and its importance in $\mathrm{L} 2$ learning.
\end{abstract}

Index Terms - language learning motivation, L2 motivational self system, intended effort, eastern languages

\section{INTRODUCTION}

Motivation has always been claimed as the source for individuals to choose what to do, how long they will stick with something, and how hard they will apply themselves when they do it (Dörnyei, 2005). Motivation determines the direction and intensity of human activity. In the field of second language acquisition (SLA), motivation has been recognised as one of the main factors that facilitate L2 acquisition. Dörnyei (2005) argued that no matter how good the curriculum and teachers are, if learners are not motivated, they are less likely to achieve satisfactory learning outcomes (p. 65).

To date, research on second language motivation has been based primarily on English as a second language or a foreign language (FL), leaving a large number of other languages missing from the field of study (Boo et al., 2015; Dörnyei \& Al-Hoorie 2017; Ushioda \& Dörnyei, 2017; Ushioda, 2017). Indeed, with the rise of global English, most of the 21st-century literature on second language acquisition (SLA) motivation seems to focus on the learning of English, which many today see as an essential educational skill alongside reading, writing, and math. However, it would be misleading for educators and governments to determine the choice and use of other languages based solely on research into the motivations for learning English (Ushioda \& Dörnyei, 2017).

A recent reviewed article (Boo et al., 2015) has shown that many early studies of L2 motivation have been criticised for focusing on a single unique Canadian context, and among the research conducted into motivation from 2005 to 2014 , the overwhelming majority (i.e., 72.67\%) of the empirical surveys were devoted to learning English as a second language. Furthermore, as synthesised by Mendoza and Phung (2019), only around 27\% of the studies were related to a language other than English (LOTE), alone or together with English. When it comes to the geographic distribution of the research and the nationalities of the research participants, there were three main locations to note - Japan, the United States, and China. Once again, East Asia dominated among the participants, who were Chinese and Japanese, leaving Southeast Asia, especially in Thailand, little known. Due to this huge "language bias", guest editors Dörnyei and Ushioda were committed to exploring the uncharted field of language learning motivation for LOTEs and other such possible language biases in a special issue of The Modern Language Journal published in 2017.

In effect, for all those concerned with promoting, supporting, and enhancing language learning outside of global English, learning about the motivations for studying LOTEs may be a vitally important issue (Ushioda \& Dörnyei, 2017). In the midst of this situation, the present study, based on the conceptual framework of L2 Motivational Self 
System (L2MSS) theory plus five other predictors, aims to closely examine the motivational profiles of learners of LOTEs, namely Chinese, Japanese, and Korean.

In line with the objectives, two research questions are addressed as follows:

(1) What are the motivational profiles of LOTEs (Chinese, Japanese, and Korean) learners?

(2) What are the relationships between eight motivational predictors and intended effort on learning LOTEs?

\section{LITERATURE REVIEW}

\section{A. Motivation}

Gardner (1985), the pioneer in defining L2 motivation, pointed out that L2 motivation refers to the willingness to learn a second language, to work toward a goal, and to derive satisfaction from the learning process. To be exact, motivation is conceptualised in three parts, which are "motivational intensity, desire to learn the language, and an attitude towards the act of learning the language" (p. 25).

For a long time, research on motivation focused on the dichotomy distinction between integrative and instrumental motivation, which are the key parts in Gardner's "socio-educational (SE) model of second language acquisition" (1985). Even in the last decade, Gardner's theory has dominated L2 motivation research. However, it wasn't until the 1990s that researchers commented on and critically debated Gardner's theory, questioning the relevance of Gardner's theory to contexts other than Canada. For example, outside of the Canadian context, the concept of integration was ineffective when the concept narrowed its sense in many learning environments (Dörnyei et al., 2006). Moreover, the theory was not supported in the contexts like China, Hungary, and Japan where English was considered as a foreign language rather than second language (Csizér \& Kormos, 2009). In these contexts, English was learned as a tool for academic purposes or self-improvement but was less commonly used as a medium of communication in everyday life (Dörnyei, 2005, 2009). Therefore, Gardner's "integrative motivation" in the social-psychosocial stage shows limitations.

\section{B. L2 Motivational Self System}

After considering the limitations of the traditional motivational system and incorporating various aspects of mainstream psychological motivation theory, Dörnyei (2005) proposed the L2 Motivational Self System (L2MSS). During the formation and development of the L2MSS, the theory of the possible self (Markus \& Nurius, 1986) and self-discrepancy (Higgins, 1987) gave a lot of support to the main components of the L2MSS - ideal L2 self and ought-to L2 self. In particular, the concept of the ideal self and the ought-to L2 self contributed significantly. Ideal L2 self is defined as "the L2-specific facet of one's 'ideal self"” (Dörnyei, 2009, p.29). It reflects an L2 learner's ideal self-image, one's aspirations for the future. Ought-to L2 self refers to "the L2-specific aspect of one's ought-to self" (Papi, 2010, p. 469). It reflects the attributes that one believes he/she should or ought to have under self-responsibility and external expectations (e.g., parents, teachers, friends, etc.). At the same time, considering that the motivation of some learners to learn an L2 does not come from future self-guides but is influenced by the classroom learning environment and previous learning experiences, Dörnyei (2005) proposed a third component of the L2MSS - L2 learning experience, which relates the "situated, 'executive' motives related to the immediate learning environment and experience" (Dörnyei, 2009, p.29), such as successful learning experiences, teachers' influences, and the impact of curricula.

In English motivation studies, ideal L2 self was considered as the strongest motivator in L2 learning, regardless of age or geographic location (e.g., Csizér \& Kormos, 2009; Ryan, 2009; Taguchi, 2013; Taguchi et al., 2009). At the same time, the ought-to L2 self was the least contributing motivator for language learning (e.g., Csizér \& Kormos, 2009; Papi, 2010; Taguchi et al., 2009). Lastly, L2 learning experience was another strong predictor of motivation to learn a language (e.g., Lamb, 2012; Papi, 2010; Ryan, 2009).

In LOTEs motivation studies, the situation is quite different from English motivation with different results across studies. Based on the L2MSS theoretical framework, the strongest motivational predictor in Europe was the ideal L2 self within the groups of 16- to17-year-old learners of English and German in Hungary (Csizér \& Lukács, 2010), and for Grade 8 Hong Kong students (ages 13-15) studying English and Mandarin (Dörnyei \& Chan, 2013). However, in a Chinese context, ought-to L2 self was the stronger motivational predictor for L3 Japanese while for L2 English it was ideal L2 self (Wang \& Zheng, 2019). The last predictor — L2 learning experience, which was highly related to global English, has been the least examined in relevant studies and has even been omitted from the questionnaires of some studies (e.g., Csizér \& Dörnyei, 2005). Yet, Huang (2019) found a significant role for learning experience in both English and eight LOTEs of Taiwanese learners.

\section{Criterion Measure and Other Possible Predictors}

This study adopted "intended effort" as a criterion measure in order to examine the level of effort that learners intend to put into learning LOTEs, since several studies (Csizér \& Kormos, 2009; Ryan, 2009; Taguchi et al., 2009) have shown that this variable was significantly related to all three components of the L2MSS in different contexts (e.g., Iran, Hungary, Japan, and Saudi Arabia). A high value of intended effort implies a high intensity of motivation.

In addition to the main predictors in the L2MSS, other factors have been shown in the literature of past studies to be important factors in language learning motivation. 
Instrumentality was distinguished by Dörnyei (2005) into two types: instrumentality-promotion and instrumentality-prevention. The former regulates positive outcomes, i.e., goals and hopefully achievements in professional and personal language success, while the latter controls negative outcomes, associated with the responsibilities and obligations that individuals perceive themselves to have towards others. Thus, instrumentality can be considered an important factor and the two types have been demonstrated in several studies (e.g., Huang, 2019; Zheng et al., 2019).

The international posture constructed by Yashima (2009) was found to be an important predictor in motivating students. International posture refers to a gesture that associates oneself with the international community rather than with a particular language group. In a study by Islam et al. (2013), it was found that students with international posture showed relatively strong motivation. Similarly, this kind of posture was found in a study by Teo et al. (2019).

Family influence is also an important factor in motivating language learning, for example, the family background had an impact on motivating Thai students to learn English and Chinese (Siridetkoon \& Dewaele, 2018); parents provided positive roles to English learning and negative roles to German learning (Csizér \& Lukács, 2010); and it was found in Japan, China, and Iran that family influences affected learners' English motivation behavior (Taguchi et al., 2009).

The last important factor is cultural/community interest. Literally and obviously, it refers to the learner's interest in the community and associated culture in which the target language is being learned. The presence of this variable was strongly proved in Huang's (2019) Taiwanese study.

\section{LOTEs in Thailand}

Since Chinese, Japanese, and Korean are, to varying degrees, related to various aspects of Thailand's economy and national wellbeing, including the labour market, tourism, culture, investment, the following section describes why these languages were targeted in the current study.

Firstly, Chinese language has been incorporated into all levels of education and various educational institutions in Thailand for more than four decades. According to the Hanban office (Hanban Thailand Office, 2015), Thailand has the highest number of Chinese language learners in Asia. Moreover, in terms of tourism in Thailand, Chinese tourists topped the list in 2018 (Ministry of Tourism and Sports, 2019), and Thailand has been cited as the most popular destination for Chinese people (World Travel Online, 2017). Therefore, Thailand is committed to training Chinese language talents for the development and construction of the country.

When it comes to Japanese, the number of Japanese companies and factories in Thailand has increased along with the close economic ties between Japan and Thailand. Japan has been the largest foreign investor in Thailand for four consecutive years (2015-2019), followed by Singapore and China (Thailand Board of Investment, 2019). Due to Japan's strong economic presence in Thailand, students who are proficient in Japanese are preferred by future employers in related industries in today's competitive job market.

Over the past decade, Thailand has also benefited from the growing number of tourists from South Korea. And Korea also ranked third only after China and Malaysia in terms of tourism statistics in 2018 (Ministry of Tourism and Sports, 2019). In addition, with the rise of the Korean wave in other Asian countries, Korean culture has also been successfully introduced into the Thai market, especially K-drama and K-music (Ainslie, 2016). In fact, Korean language study is the third most popular choice for Thai students after Chinese and Japanese (Thandee, 2008). Therefore, Korean language is also one of the most popular languages of choice among students in Thailand.

\section{MATERIALS AND METHODS}

To fulfil the two research questions of (1) the motivational profiles of LOTEs (Chinese, Japanese, and Korean) learners, and (2) the relationships between eight motivational predictors and intended effort on learning LOTEs, the current study employs a mixed-method design with questionnaires and interviews. The following section explains the methodology employed in this study.

\section{A. Instruments}

Three versions of the questionnaires were used in this study (motivation to learn Chinese, Japanese, and Korean respectively), each of which was parallel in content. The questionnaire consisted of two parts. The first part contained items about background information. The second part consisted of nine subscales measuring each of the nine constructs, with each subscale consisting of four items on a six-level Likert scale. The six-level Likert scales ranged from " 1 (Strongly Disagree)" to "6 (Strongly Agree)".

The questionnaires used in this study adopted items from well-established motivational questionnaires used in related studies with sufficient validity and reliability (i.e., Papi, 2010; Taguchi et al., 2009; Yashima, 2009). A total of nine constructs were chosen for this study, as every single construct had been shown to be an important motivational predictor in previous related studies (e.g., Csizér \& Kormos, 2009; Csizér \& Lukács, 2010; Huang, 2019; Islam et al., 2013; Ryan, 2009; Siridetkoon \& Dewaele, 2018; Taguchi et al., 2009; Teo et al., 2019; Zheng et al., 2019). Some items were removed and modified due to their similarity in meaning to other items and the time limit for completion. Since all undergraduate students were LOTE learners with Thai as their first language, all items were translated into Thai. A test of the reliability of the translation was performed to ensure that the content of the Thai questions was identical to the 
original English version. The question items were validated by three experts to ensure content validity. A Cronbach's Alpha reliability analysis was run to check the reliability of each subscale and the overall alpha was .836 (as shown in Table 1).

TABLE 1

RELIABILITY ANALYSIS OF THE SUBSCALES

\begin{tabular}{|c|c|c|}
\hline Variable & No. of Items & Cronbach's Alpha \\
\hline Intended effort & 4 & .826 \\
\hline Ideal L2 self & 4 & .887 \\
\hline Ought-to L2 self & 4 & .900 \\
\hline L2 learning experience & 4 & .879 \\
\hline Instrumentality-promotion & 4 & .884 \\
\hline Instrumentality-prevention & 4 & .791 \\
\hline International posture & 4 & .771 \\
\hline Family influence & 4 & .743 \\
\hline Cultural/community interest & 4 & .847 \\
\hline Total & 36 & .836 \\
\hline
\end{tabular}

Interviews were employed in this study to mitigate the biases and weaknesses created by a single questionnaire and also increase the credibility and validity of the research instrument. If the participants were willing to participate in the interview after the authors' request, they filled in the contact information in the questionnaire. Considering the difficulties of conducting research in person during the current Covid-19 pandemic, interviews were conducted in Thai via a call on Line application after completion of the questionnaire for those who provided contact information.

\section{B. Participants}

The participants were made up of a total of 95 undergraduate students, who were enrolled in one or more elective courses studying Chinese, Japanese, or Korean language. The participants were recruited through a convenient sampling technique on a voluntary basis. Moreover, a total of eight participants were willing to participate in a further interview session, which lasted for 15 minutes per interviewee.

\section{Data Collection}

Once the research project was IRB cleared, and permission to collect data at the research site was granted by the college's administrator, the lecturers of each language were contacted. It is noteworthy that the data collection process was undertaken during the suspension of onsite learning activities, the researchers, therefore, collected data via online channels, with the permission of each respective language lecturer. A phone interview was conducted through Line application with the participants who agreed to participate in the interview session.

\section{Data Analysis}

Descriptive statistics and a Pearson's correlation were used to analyse data from the questionnaires. Regarding the qualitative data, a content analysis was employed to obtain the key terms and to complement the quantitative findings.

\section{RESULTS}

This section reports the findings of this study, both quantitative and qualitative. Quantitative findings are presented through descriptive data and a Pearson's correlation, while qualitative findings are presented in the form of transcriptions of interviews with respondents.

\section{A. Quantitative Results from Eastern Languages}

In order to identify the motivational characteristics of undergraduate students studying Chinese, Japanese, and Korean, the descriptive statistics of the criterion measure and motivational predictors among participants are shown in Table 2.

TABLE 2

DESCRIPTIVE STATISTICS AMONG CHINESE, JAPANESE, AND KOREAN LEARNERS $(N=95)$

\begin{tabular}{lcccccc}
\hline \multirow{2}{*}{$\begin{array}{l}\text { Constructs } \\
\end{array}$} & \multicolumn{2}{c}{$\begin{array}{c}\text { Chinese Learners } \\
(\boldsymbol{n = 3 5})\end{array}$} & $\begin{array}{c}\text { Japanese Learners } \\
(\boldsymbol{n = 3 1})\end{array}$ & $\begin{array}{c}\text { Korean Learners } \\
(\boldsymbol{n}=\mathbf{2 9})\end{array}$ \\
\cline { 2 - 7 } & $\boldsymbol{M}$ & $\boldsymbol{S D}$ & $\boldsymbol{M}$ & $\boldsymbol{S D}$ & $\boldsymbol{M}$ & $\boldsymbol{S D}$ \\
\hline Intended effort & 4.76 & 0.99 & 4.17 & 0.94 & 5.14 & 0.59 \\
Ideal L2 self & 4.24 & 1.31 & 3.82 & 0.91 & 4.74 & 1.21 \\
Ought-to L2 self & 3.31 & 1.51 & 2.38 & 0.95 & 2.00 & 1.03 \\
L2 learning experience & 4.90 & 1.03 & 4.50 & 0.79 & 5.06 & 0.84 \\
Instrumentality-promotion & 4.82 & 1.05 & 4.10 & 1.02 & 4.44 & 1.28 \\
Instrumentality-prevention & 3.07 & 1.26 & 2.38 & 1.13 & 2.14 & 0.79 \\
International posture & 4.86 & 1.05 & 4.71 & 0.92 & 5.19 & 0.73 \\
Family influence & 3.26 & 1.26 & 2.66 & 0.84 & 2.29 & 0.91 \\
Cultural/community interest & 4.71 & 0.18 & 5.33 & 0.87 & 5.40 & 0.71 \\
\hline
\end{tabular}

The questionnaires were administered through a Likert scale of one to six (strongly disagree to strongly agree). The 
intended effort values of three eastern languages all rated above 4, indicating a high motivation intensity in learning the three languages. Among eight predictors, L2 learning experience scored the highest among Chinese learners $(M=4.90$, $S D=1.03)$, while culture/community interest scored the highest among Japanese learners $(M=5.33, S D=0.87)$ and Korean learners $(M=5.40, S D=0.71)$. All language learners showed commonalities in ought-to L2 self, instrumentality-prevention, and family influence, which scored under 4 and the lowest among the eight predictors. Additionally, ideal L2 self, L2 learning experience, instrumentality-promotion, international posture, and culture/community interest all had strong influence on learners' motivation in learning all three languages.

A Pearson's correlation analysis revealed the relationships between the intended learning effort with other variables as follows. For Chinese learners, the intended effort showed a positive relationship with ideal L2 self $(r=.680, p$ $=.000)$, L2 learning experience $(r=.863, p=.000)$, instrumentality-promotion $(r=.651, p=.000)$, international posture $(r=.275, p=.003)$, and culture/community interest $(r=.426, p=.000)$. For Japanese learners, it showed a positive relationship with ideal L2 self $((r=.390, p=.030)$, L2 learning experience $(r=.546, p=.001)$, culture/community interest $(r=.433, p=.015)$, but negative relationship with instrumentality-prevention $(r=-.420, p$ $=.019)$. For Korean learners, the intended effort showed a positive relationship with ideal L2 self $(r=.655, p=.000)$, L2 learning experience $(r=.715, p=.000)$, and international posture $(r=.446, p=.015)$.

TABLE 3

CORRELATIONS BETWEen CRITERION MEASURE AND PREDICTORS AMONG CHINESE, JAPANESE, AND KoREAN LEARNERS

\begin{tabular}{|c|c|c|c|c|c|c|}
\hline \multirow{2}{*}{ Intended effort } & \multicolumn{2}{|l|}{ Chinese $(n=35)$} & \multicolumn{2}{|l|}{ Japanese $(n=31)$} & \multicolumn{2}{|l|}{ Korean $(n=29)$} \\
\hline & Pearson Correlation & Sig. & Pearson Correlation & Sig. & Pearson Correlation & Sig. \\
\hline Ideal L2 self & $.680^{* *}$ & .000 & $.390 *$ & .030 & $.655^{* *}$ & .000 \\
\hline Ought-to L2 self & .264 & .126 & -.228 & .216 & -.052 & .791 \\
\hline L2 learning experience & $.863 * *$ & .000 & $.546^{* * *}$ & .001 & $.715^{* *}$ & .000 \\
\hline Instrumentality-promotion & $.651 * *$ & .000 & -.019 & .919 & .139 & .472 \\
\hline Instrumentality-prevention & .300 & .080 & $-.420 *$ & .019 & -.109 & .573 \\
\hline International posture & $.275^{*}$ & .003 & .209 & .258 & $.446^{*}$ & .015 \\
\hline Family influence & -.274 & .092 & -.312 & .087 & -.103 & .594 \\
\hline Cultural/community interest & $.426^{*}$ & .000 & $.433 *$ & .015 & .346 & .066 \\
\hline
\end{tabular}

\section{B. Supportive Findings from Interviews about Motivation for Learning Chinese}

By analysing the participants' interview transcription, the results showed that Chinese learners were motivated by their ideal L2 self, L2 learning experience, instrumentality-promotion, family influence, and cultural/community interests.

Regarding ideal L2 self, one participant expressed his motivation for learning Chinese as being a result of his Chinese family background and his personal desire to have a Chinese girlfriend.

I like learning Chinese because many companies come from China. Nowadays, the Chinese economy is growing. China is developing into number one, so I think if I learn Chinese, I will have the opportunity to work in a Chinese company and thus be able to meet more Chinese girls. (CS1)

Apart from personal desire, two of the three participants expressed a desire for multilingualism and emphasised its importance for future work. For example,

I feel it is important because I want to use the language for my future career. Learning many languages is very important. (CS2)

As the strongest predictor in Chinese learners' motivational profiles, L2 learning experience was found in the answers of all respondents. One respondent thought the Chinese language was interesting and the teacher had a good personality, as he stated:

Because it is easy to understand and the teacher is kind. (CS1)

Similarly, another respondent explained:

I find the class interesting, maybe because of the atmosphere and also the teacher. (CS3)

A student who had experience studying in China also expressed that:

As I keep learning, I feel that it is a very interesting language, both written and spoken. And I went on exchange in China for six and a half months, too. I felt that the whole culture and everything are interesting. (CS2)

Instrumentality-promotion was also found in two respondents' profiles. One had the desire to study abroad and the other hoped to find a job to achieve her life goal by learning Chinese.

And now it will be my goal in life. I want to be successful in my life goal. As I have set aside, I want to have a house, I want to be able to care for my parents. [...] Yeah. Because as I said, Chinese is a useful language that I can use to build my career in the future. And if I can, then I will have a high salary. With a high salary, my life goal can be achieved. (CS2)

One participant indicated that she chose to learn Chinese due to advice from a family member, which reflected a family influence.

Oh, actually, I wanted to learn Japanese, but my grandfather suggested me to learn Chinese first if I will learn Japanese. Because Chinese is the foundation of the Japanese language, so I am now learning Chinese. (CS2) 
Finally, two respondents mentioned their interest in Chinese culture, including celebrities, singers, and TV series. For example:

Oh, I like stars, performers, singers and that kind of thing. I can also say I like TV series, listening to the songs to see what is sung, and then I can understand them without reading the subtitles. (CS3)

In short, the interview data supported the quantitative findings that students who were enrolled in Chinese courses were motivated by personal desire, job considerations, classroom experience, personal improvement, and cultural interests. However, the qualitative data also revealed family members as a motivational source for one student, which was not significant in the quantitative data set.

\section{Supportive Findings from Interviews about Motivation for Learning Japanese}

Among the two interviewed Japanese language learners, their motivation came mainly from cultural/community interest, L2 learning experience, and instrumentality-promotion.

When asked why they studied Japanese, both respondents referred to traveling as a reason.

Oh, I like Japan anyway. So, I thought that if I could learn Japanese, I would be able to communicate, or something like that. And I've also travelled to Japan. (JS1)

In addition to traveling, another student also mentioned the idea of studying in Japan for further education and their interest in Japanese culture.

That is, with the thought that maybe I will study further in Japan and because of the culture ... and travel, something like that, because I've been there once but using English and it was not very convenient, like they don't speak English very fluently there. (JS2)

One student noted that the familiarity with the Japanese language made him feel that the study time went by fast.

...If I were to choose a third language, I would choose to study Japanese because I like it the most and then I am familiar with it. Because I have watched Japanese shows, cartoons, and so on, it makes me familiar with Japanese and makes the learning time goes faster. (JS1)

Regarding the instrumentality-promotion, this respondent also stated that Japanese was a good skill and advantageous for future jobs.

If it happens as if there is a job offer back then, if I can speak Japanese, it is a good add-on for me. (JS1)

In summary, the interview data supported the quantitative findings that students who were enrolled in Japanese courses were motivated by personal goals, familiarity with the target language, and cultural interests (such as travel and cartoons). Nonetheless, the interview data showed that the students also considered professional skill improvement as a motivational source, which differed from the quantitative data.

\section{Supportive Findings from Interviews about Motivation for Learning Korean}

After interviewing three respondents, five motivational predictors were found among them, covering ideal L2 self, ought-to L2 self, L2 learning experience, instrumentality-promotion, and cultural/community interest.

The first two predictors were present in the responses of one individual. She expressed that learning Korean would enable her to better communicate and connect with foreign students in this language.

If I learn it, I understand it and I can talk to other people. And I can do other things, like in class, the teacher said there is something like a party between Thai and foreign students. And if I have the foundation, when I go to deal with Koreans, I can use Korean to communicate and there will be more connections. (KS1)

However, she also reported that she encountered obstacles in learning Korean and when the two conflicted, she may have to give up her Korean course. This was also aligned with the quantitative results that it made the motivation decrease when the ought-to L2 self increased.

... But if it's specific to me, it would be my advisor who doesn't let me choose to study. Yeah. Actually, I have the right to choose which class to take as an elective, right? ... But when all my credits were completed, I asked to learn more, something like this. But my advisor in my faculty doesn't seem to want me to learn ... I think this is the greatest obstacle. Because if the teacher wants me to work, I mean the advisor wants me to work, or something like that, then I have to withdraw from studying Korean if there is a time conflict or something like that. (KS1)

In terms of L2 learning experience, one respondent indicated that their teacher played a role in motivating them to learn Korean.

It's fun because the teacher is a part of what makes learning Korean interesting. And because of the kindness and patience of the teacher, I feel that I can keep learning. (KS3)

Similar to Chinese learners and Japanese learners, instrumentality-promotion also emerged among two Korean learners, one indicating that Korean language could support her future work, and the other indicating that Korean language was helpful in achieving her special goal.

It's like I know Thai and I know English. But if I know Korean, it will help support me on another side as well. [...] Yeah. Like (it's important) in work. I think it would be better if I know than if I don't. (KS3)

... Another thing is that I want to study abroad, and I am looking at many places, such as China, Taiwan, or the European side. Then Korea was one of them. Because I watched YouTube, and there was a senior who is a Thai and got a scholarship from the Korean government. Although it's not specifically related to the Korean language, he was able to study there. (KSI) 
Last but not least, all three respondents cited an interest in culture, including a fondness for TV shows, movies, singers, and travel. For instance:

Because I have special interests. The first is that I am inspired by Korean dramas, and I want to travel to Korea. Like, I want to learn the culture so that when traveling I would be able to communicate with them and read, and so on. (KS3)

In other words, the interview data supported the quantitative findings that students who were enrolled in Korean courses were motivated by learning experience, social interaction, and career development. Although it was not quantitatively significant, students also showed a preference for Korean language due to cultural factors. It is also noteworthy to mention that past learning experience was not a motivational source for the students.

\section{DISCUSSION}

The results showed that L2 learning experience was the strongest predictor of motivation across all language groups highlighted in this study. According to these results, L2 learning experience (classroom learning experiences, the roles of teachers, and learning experience of a previously targeted language country) was more likely to increase motivation than the ideal L2 self component. This finding is consistent with those of Papi (2010) and Huang (2019). As Dörnyei (2009) stated, some students' initial motivation does not come from the pursuit of an ideal self-image, but rather from an enjoyable learning experience during the learning process. Language experiences can contribute to students' positive language achievements. The indirect effect of enjoying the support of teachers and students in English language achievement was achieved through enjoying English language learning (Jin \& Zhang, 2018). In a similar vein, L2 learning experience was found to have the strongest relationship with student achievement (Subekti, 2018).

This result may be related to the fact that these students were voluntarily choosing these languages as electives and that most of them have been studying these languages for less than a year, which is why most of their motivation came from their learning experiences in the classroom. Therefore, the influence of learning conditions, environment, and learners' learning experiences on motivation should be properly considered in teaching.

Closely following L2 learning experience, ideal L2 self played the second most important role for Chinese and Korean learners. This is similar to You and Dörnyei's (2014) study, where ideal L2 self ranked second, after attitude to L2 learning. Meanwhile, cultural and community interest was also shown to be highly correlated with intended effort for Chinese and Japanese learners in the present study, which is analogous to other studies, such as group two of Hungarian students learning English in Csizér \& Dörnyei's study (2005) and Japanese students learning English (Taguchi et al., 2009). Although the correlation between cultural/community interest and intended effort among Korean language learners was not significant, all three interviewees expressed some interest in Korean culture. Many times, they mentioned wanting to watch TV programs or listen to song lyrics in the target language without translating the subtitles, which affirms the stimulating effect of cultural/community interest on language learning. This is insightful for educators and could lead them to add some cultural elements of the target country to the classroom learning in order to increase students' interest.

Instrumentality-promotion and instrumentality-prevention showed strong relationships among Chinese students and Korean students, respectively. It is worth noting that the former had a positive correlation while the latter had a negative correlation. This suggests that individuals were willing to invest time and effort in learning Chinese in order to achieve their goals in terms of language for professional or personal achievement, and conversely, external responsibilities and obligations were given to demotivate students to study Japanese in order to avoid certain negative outcomes such as failing an exam. This is probably why Japanese learners had the lowest intended effort among the three language learners. Accordingly, it can be argued that it is important for teachers to increase students' sense of achievement in the learning process.

The role of international posture in students' language learning should not be underestimated either, as it appeared in the results examining Chinese and Korean learners. In line with Islam et al.'s (2013) study, students with international posture showed stronger motivation. Moreover, some students mentioned their multilingual posture, expressing a desire to learn multiple languages, in order to improve their vocational skills. This supported the findings in Zheng et al. (2019) that the multilingual posture was salient for self-motivated learners' Spanish learning.

Ought-to L2 self and family influence showed no significant relationship with intended effort in any language group. The current findings were in line with Csizér \& Kormos (2009), who found the role of ought-to L2 self was marginal and weak in students' language learning. According to the interview data, only one student mentioned stress that came from external sources. The rest of them all expressed that their family and people around them all supported their choice in learning eastern languages, which made sense as these two variables did not affect students' effort in learning LOTEs.

\section{CONCLUSION}

This study examined the motivational characteristics of undergraduate students learning Chinese, Japanese, and Korean by applying motivational predictors from Dörnyei's L2MSS, instrumentality-promotion, instrumentality-prevention, international posture, family influence, and cultural/community interest, with intended effort as a measure of motivation. The correlations between these motivational predictors and intended effort were also 
investigated. The results revealed that the students showed high levels of motivation in learning East Asian languages. A strong linear relationship was found between L2 learning experience with all languages studied, followed by the ideal L2 self component. In addition, students' intended effort had a positive relationship with instrumentality-promotion, international posture, and cultural/community interest in Chinese learners; cultural/community interest in Japanese learners, and international posture in Korean learners. However, instrumentality-prevention and intended effort were found to be negatively related for Japanese learners.

It has to be said that there were some limitations to this study. Firstly, the sample of this study was small and unbalanced between the number of language groups. Secondly, there was a gender imbalance, with female students predominating among all language learners. Furthermore, the majority of all language groups enrolled in the respective class for less than one year in length and the results cannot be applied to learners who have been studying for a longer period of time. Therefore, the findings cannot be generalised to all Chinese, Japanese, and Korean motivational-intended efforts. Since there were participants who had been learning the language for a long time and who mentioned in the interviews that their motivation was different at the beginning than it is now, more research is needed to investigate whether students' motivation could progress if they take more courses, or are enrolled on courses for a longer time. Such studies could inform as to whether the long-time learners have different motivational-intended learning effort levels, and how they differ from that of short-time learners. In addition, the role of L2 learning experience needs to be further examined in other languages.

\section{ACKNOWLEDGEMENTS}

The authors appreciate the three course lecturers' help and students' participation in this research.

\section{REFERENCES}

[1] Ainslie, M. J. (2016). K-dramas across Thailand: Constructions of Koreanness and Thainess by contemporary Thai consumers. The Asia-Pacific Journal, 14(7), 1-13.

[2] Boo, Z., Dörnyei, Z., \& Ryan, S. (2015). L2 motivation research 2005-2014: Understanding a publication surge and a changing landscape. System, 55, 145-157. https://doi.org/10.1016/j.system.2015.10.006

[3] Csizér, K., \& Dörnyei, Z. (2005). Language learners' motivational profiles and their motivated learning behavior. Language Learning, 55(4), 613-659. https://doi.org/10.1111/j.0023-8333.2005.00319.x

[4] Csizér, K., \& Kormos, J. (2009). 5. Learning Experiences, Selves and Motivated Learning Behaviour: A Comparative Analysis of Structural Models for Hungarian Secondary and University Learners of English. In Z. Dörnyei, \& E. Ushioda (Eds.), Motivation, Language Identity and the L2 Self (pp. 98-119). Multilingual Matters. https://doi.org/10.21832/9781847691293-006

[5] Csizér, K., \& Lukács, G. (2010). The comparative analysis of motivation, attitudes and selves: The case of English and German in Hungary. System, 38(1), 1-13. https://doi.org/10.1016/j.system.2009.12.001

[6] Dörnyei, Z. (2005). The psychology of the language learner: Individual differences in second language acquisition. Routledge. https://doi.org/10.4324/9781410613349

[7] Dörnyei, Z. (2009). The L2 motivational self system. In Dörnyei, Z., \& Ushioda, E. (Eds.), Motivation, Language Identity and the L2 Self (pp. 9-11). Multilingual Matters. https://doi.org/10.21832/9781847691293-003

[8] Dörnyei, Z., \& AL-HOORIE, A. H. (2017). The motivational foundation of learning languages other than global English: Theoretical issues and research directions. The Modern Language Journal, 101(3), $455-468$. https://doi.org/10.1111/modl.12408

[9] Dörnyei, Z., \& Chan, L. (2013). Motivation and vision: An analysis of future L2 self images, sensory styles, and imagery capacity across two target languages. Language Learning, 63(3), 437-462. https://doi.org/10.1111/lang.12005

[10] Dörnyei, Z., Csizér, K., \& Németh, N. (2006). Motivation, language attitudes and globalisation: A Hungarian perspective. Multilingual Matters. https://doi.org/10.21832/9781853598876

[11] Gardner, R.C. (1985). Social Psychology and Second Language Learning: The Role of Attitudes and Motivation. Edward Arnold. https://doi.org/10.1037/h0083787

[12] Hanban Thailand office. (2015). HANBAN Thailand's Office Report. Bangkok: Education Office of The Embassy of the People's Republic of China in Thailand

[13] Higgins, E. T. (1987). Self-discrepancy: a theory relating self and affect. Psychological review, 94(3), 319-340. https://doi.org/10.1037/0033-295X.94.3.319

[14] Huang, S. C. (2019). Learning experience reigns - Taiwanese learners' motivation in learning eight additional languages as compared to English. Journal of Multilingual and Multicultural Development, 40(7), 576-589. https://doi.org/10.1080/01434632.2019.1571069

[15] Islam, M., Lamb, M., \& Chambers, G. (2013). The L2 motivational self system and national interest: A Pakistani perspective. System, 41(2), 231-244. https://doi.org/10.1016/j.system.2013.01.025

[16] Jin, Y., \& Zhang, L. J. (2018). The dimensions of foreign language classroom enjoyment and their effect on foreign language achievement. International Journal of Bilingual Education and Bilingualism, 24(7), 948-962. https://doi.org/10.1080/13670050.2018.1526253

[17] Lamb, M. (2012). A Self System Perspective on Young Adolescents' Motivation to Learn English in Urban and Rural Settings. Language Learning, 62(4), 997-1023. https://doi.org/10.1111/j.1467-9922.2012.00719.x

[18] Markus, H., \& Nurius, P. (1986). Possible selves. American Psychologist, 41(9), 954-969. https://doi.org/10.1037/0003-066X.41.9.954 
[19] Mendoza, A., \& Phung, H. (2019). Motivation to learn languages other than English: A critical research synthesis. Foreign Language Annals, 52(1), 121-140. https://doi.org/10.1111/flan.12380

[20] Ministry of Tourism and Sports. (2019, October 9). Tourism receipts from international tourist arrivals 2018. Retrieved December 8, 2021, from https://www.mots.go.th/more_news_new.php?cid=529

[21] Papi, M. (2010). The L2 motivational self system, L2 anxiety, and motivated behavior: A structural equation modeling approach. System, 38(3), 467-479. https://doi.org/10.1016/j.system.2010.06.011

[22] Ryan, S. (2009). 6. Self and Identity in L2 Motivation in Japan: The Ideal L2 Self and Japanese Learners of English. In Z. Dörnyei, \& E. Ushioda (Eds.), Motivation, Language Identity and the L2 Self (pp. 120-143). Multilingual Matters. https://doi.org/10.21832/9781847691293-007

[23] Siridetkoon, P., \& Dewaele, J.-M. (2018). Ideal self and ought-to self of simultaneous learners of multiple foreign languages. International Journal of Multilingualism, 15(4), 313-328. https://doi.org/10.1080/14790718.2017.1293063

[24] Subekti, A. S. (2018). L2 Motivational Self System and L2 achievement: A study of Indonesian EAP learners. Indonesian Journal of Applied Linguistics, 8(1), 57-67. https://doi.org/10.17509/ijal.v8i1.11465

[25] Taguchi, T. (2013). 10. Motivation, Attitudes and Selves in the Japanese Context: A Mixed Methods Approach. In M. Apple, D. Da Silva \& T. Fellner (Ed.). Language Learning Motivation in Japan (169-188). Multilingual Matters. https://doi.org/10.21832/9781783090518-012

[26] Taguchi, T., Magid, M. \& Papi, M. (2009). 4. The L2 Motivational Self System among Japanese, Chinese and Iranian Learners of English: A Comparative Study. In Z. Dörnyei \& E. Ushioda (Ed.), Motivation, Language Identity and the L2 Self (pp. 66-97). Multilingual Matters. https://doi.org/10.21832/9781847691293-005

[27] Teo, T., Hoi, C. K. W., Gao, X., \& Lv, L. (2019). What motivates Chinese university students to learn Japanese? understanding their motivation in terms of 'posture'. The Modern Language Journal, 103(1), 327-342. https://doi.org/10.1111/modl.12546

[28] Thailand Board of Investment. (2019). Annual foreign direct investment report (Thai only). Retrieved December 8, 2021, from https://www.boi.go.th/index.php?page=statistics_situation

[29] Thandee, D. (2008). Continuity of Korean studies in Thailand. In International Conference on Korea Day, on the occasion of the 50th anniversary celebration of Korean-Thai relations, Chiangmai Rajabhat University, Thailand.

[30] Ushioda, E. (2017). The impact of global English on motivation to learn other languages: Toward an ideal multilingual self. The Modern Language Journal, 101(3), 469-482. https://doi.org/10.1111/modl.12413

[31] Ushioda, E., \& Dörnyei, Z. (2017). Beyond global English: Motivation to learn languages in a multicultural world: Introduction to the special issue. The Modern Language Journal, 101(3), 451-454. https://doi.org/10.1111/modl.12407

[32] Wang, Z., \& Zheng, Y. (2019). Chinese university students' multilingual learning motivation under contextual influences: a multi-case study of Japanese majors. International Journal of Multilingualism, 18(3), 384-401. https://doi.org/10.1080/14790718.2019.1628241

[33] World Travel Online. (2017, February 3). Chinese Outbound Tourism Statistics in 2016: 122 Million Chinese Tourists Make Outbound Trips, Spend \$109.8 Billion. Retrieved December 8, 2021, from http://lvyou168.cn/tools/doPrint_en.aspx?main_id=201723163745476

[34] Yashima, T. (2009). 7. International Posture and the Ideal L2 Self in the Japanese EFL Context. In Z. Dörnyei \& E. Ushioda (Ed.), Motivation, Language Identity and the L2 Self (pp. 144-163). Multilingual Matters. https://doi.org/10.21832/9781847691293-008

[35] You, C., \& Dörnyei, Z. (2014). Language Learning Motivation in China: Results of a Large-Scale Stratified Survey. Applied Linguistics, 37(4), 495-519. https://doi.org/10.1093/applin/amu046

[36] Zheng, Y., Lu, X., \& Ren, W. (2019). Profiling Chinese university students' motivation to learn multiple languages. Journal of Multilingual and Multicultural Development, 40(7), 590-604. https://doi.org/10.1080/01434632.2019.1571074

Luoling Yang (first author) was born in Hubei, China in 1996. She is currently a postgraduate student at Applied Linguistics program, Faculty of Liberal Arts, Mahidol University, Thailand. Her research interests include second language teaching and second language acquisition. She may be reached at luoling.yan[at]student.mahidol.edu

Natthapong Chanyoo (corresponding author) is an assistant professor in the Graduate Program in Applied Linguistics at the Faculty of Liberal Arts, Mahidol University. His research interests include second language acquisition, psychology of language learning and foreign language education. He may be reached at natthapong.cha[at]mahidol.edu 